Tersedia online di: http://ejournal-balitbang.kkp.go.id/index.php/jra

\title{
DETEKSI DINI Enterocytozoon hepatopenaei (EHP) PADA UDANG VANAME (Litopenaeus vannamei) MENGGUNAKAN METODE PCR (POLYMERASE CHAIN REACTION)
}

\author{
Annisa Fitriah Faisal" dan Adi Pancoro \\ Kelompok Keilmuan Genetika dan Bioteknologi Molekuler, Sekolah IImu dan Teknologi Hayati, \\ Institut Teknologi Bandung \\ Jl. Ganesha No.10, Lb. Siliwangi, Coblong, Kota Bandung, Jawa Barat 40132
}

(Naskah diterima: 9 Juli 2018; Revisi final: 9 November 2018; Disetujui publikasi: 9 November 2018)

\begin{abstract}
ABSTRAK
Sejak akhir tahun 2014, wabah kotoran putih atau yang sering disebut juga WFD (White Feces Disease), merupakan salah satu masalah yang sering terjadi pada petambak udang di Indonesia. Wabah ini diketahui disebabkan oleh Enterocytozoon hepatopenaei (EHP) dan telah mengakibatkan retardasi pertumbuhan hingga kematian pada udang. Hingga saat ini, penyakit WFD dapat dideteksi dengan cara uji histologi, hibridisasi in situ, dan PCR. Penelitian ini bertujuan untuk mendapatkan metode deteksi dini penyakit EHP pada udang vaname dengan metode PCR melalui perancangan primer yang spesifik dan sensitif. Pada penelitian ini dilakukan isolasi EHP pada udang vaname yang terinfeksi, kemudian dideteksi dengan metode PCR yang mentarget SWP (spore wall protein) dari EHP serta pengujian spesifitas dan sensitivitasnya. Hasil yang diperoleh menunjukkan bahwa EHP dapat diisolasi dari udang yang terinfeksi dan dapat didesain dua pasang primer yaitu SWP-EHP1 dan SWP-EHP3 yang mentarget spore wall protein EHP. Kedua primer ini dapat digunakan untuk deteksi EHP menggunakan PCR, dengan produk PCR pada primer SWP-EHP1 yaitu 398 bp dan primer SWP-EHP3 sebesar $415 \mathrm{bp}$, serta nilai suhu annealing optimal pada $48^{\circ} \mathrm{C}$. Hasil pengujian sensitivitas primer, diketahui bahwa primer SWP-EHP1 dapat mendeteksi EHP hingga jumlah DNA target sebanyak 7,74 $\times 10^{2}$ kopi sedangkan primer SWP-EHP3 dapat mendeteksi hingga 16,2 × 102 kopi.
\end{abstract}

\section{KATA KUNCl: $\quad$ udang vaname; WFD; Enterocytozoon hepatopenaei; PCR}

ABSTRACT: Detection of EHP (Enterocytozoon hepatopanaei) from whiteleg shrimp (Litopenaeus vannamei) by Polymerase Chain Reaction (PCR) method. By: Annisa Fitriah Faisal and Adi Pancoro

Since 2014, white feces disease (WFD) is one of the emerging problems for whiteleg shrimp farming industries in Indonesia. This outbreak is known to be caused by Enterocytozoon hepatopenaei (EHP) infection to shrimp. EHP infection resulted in growth retardation to a mass mortality in shrimp. To date, WFD can be detected by histology, in situ hybridization and PCR. This study aimed to obtain an early detection method of EHP on whiteleg shrimp by PCR method through specific and sensitiveprimers design. In this study, we isolated the DNA of EHP from infected whiteleg shrimp, then detected by PCR method which targeted spore wall protein (SW P) from EHP as well as sensitivity and specificity testing. As a result, EHP can be isolated from infected shrimp and can be designed 2 pairs of primers (SWPEHP1 and SW P-EHP3) targeting spore wall protein of EHP. These primers could be used for EHP detection using PCR, with PCR products from primers SW P-EHP1 was 398 bp and from SW P-EHP3 primers was 415 bp, with an optimum annealing temperature of $48^{\circ} \mathrm{C}$. Primers sensitivity test results revealed that primers SWP-EHP1 could detect EHP to $7.74 \times 10^{2}$ copies while the primers SWP-EHP3 could detect up to $16.2 \times 10^{2}$ copies.

KEYWORDS: whiteleg shrimp; WFD; Enterocytozoon hepatopenaei; PCR

\footnotetext{
\# Korespondensi: Kelompok Keilmuan Genetika dan

Bioteknologi Molekuler, Sekolah IImu dan Teknologi Hayati,

Institut Teknologi Bandung. Jl. Ganesha No.10, Lb. Siliwangi,

Coblong, Kota Bandung, Jawa Barat 40132

Tel. + 628989387809

E-mail: annisa.fitriah.faisal@ gmail.com
} 


\section{PENDAHULUAN}

Udang vaname merupakan salah satu komoditas ekspor perikanan andalan Indonesia yang memiliki nilai jual tinggi. Komoditas ini berkontribusi besar dalam perolehan devisa negara dengan total nilai ekspor perikanan mencapai 30-55\% Pada tahun 2011 hingga 2014 volume ekspor udang Indonesia mengalami peningkatan yang cukup signifikan yaitu dari 158.062 ton dengan nilai ekspor US\$ 1.309 .674 menjadi sebesar 196.623 ton dengan nilai ekspor US\$ 2.140.862 (Aristiyani, 2017). Meningkatnya volume ekspor udang juga sejalan dengan meningkatnya produksi udang setiap tahunnya. Menurut data Dirjen Perikanan Budidaya (2014), produksi udang vaname selama lima tahun terakhir dari tahun 2010-2014 terus mengalami peningkatan rata-rata sebesar 20,49\%

Seiring dengan meningkatnya produksi udang, kegiatan budidaya komoditas ini tidak terlepas dari berbagai masalah terutama yang disebabkan oleh adanya infeksi penyakit. Penyakit udang merupakan salah satu masalah bagi pembudidaya udang dan menjadi faktor pembatas bagi pengembangan budidaya udang (Selvin et al., 2015). Pada lima tahun terakhir ini, Enterocytozoon hepatopenaei (EHP) merupakan parasit mikrosporidian yang bertanggung jawab dalam terjadinya wabah WFD (White Feces Disease) yang mengakibatkan penghambatan pertumbuhan pada udang hingga kematian (Rajendran et al., 2016). Penyakit ini baru teridentifikasi pada tahun 2009 di Thailand dan saat ini telah menyebar ke beberapa negara di Asia Tenggara termasuk Indonesia. Beberapa wilayah yang terkena dampak wabah WFD di Indonesia di antaranya Jawa Tengah, Jawa Barat, Sumatera Utara, Lampung, Bali, Lombok, dan Sulawesi (Tang et al., 2016). Kerugian ekonomi yang disebabkan oleh infeksi EHP ini semakin berkembang sehingga dianggap menjadi ancaman bagi industri budidaya udang di tanah air. Maka dari itu diperlukan pengembangan metode diagnosis yang spesifik dan sensitif agar patogen dapat dimonitor dan ditanggulangi dengan cepat.

Saat ini, sudah dikembangkan metode deteksi EHP pada udang melalui uji histologi, hibridisasi in situ dan PCR. Metode deteksi PCR yang telah ada yaitu mentarget gen 18S rRNA EHP yang memungkinkan memberikan hasil positif palsu dikarenakan reaktivitas silang. Pada penelitian ini dilakukan perancangan primer spesifik untuk uji PCR EHP pada udang dengan mentarget SWP (Spore Wall Protein) yang terdapat pada EHP. SWP diketahui memiliki fungsi menjaga morfologi spora dan cekaman lingkungan serta memiliki peranan penting dalam proses infeksi terhadap sel inang (Yang et al., 2014). Berdasarkan hal tersebut maka tujuan dari penelitian ini adalah melakukan upaya deteksi keberadaan infeksi EHP secara dini dengan merancang primer spesifik dan sensitif untuk uji PCR pada udang vaname.

\section{BAHAN DAN METODE}

\section{Perancangan primer (in silico)}

Perancangan primer dilakukan melalui studi in silico dimulai dengan mengumpulkan semua sekuen spore wall protein Enterocytozoon hepatopenaei (SWP EHP) yang terdapat pada database GenBank NCBI (https:// www.ncbi.nlm.nih.gov/). Semua sekuen yang diperoleh dilakukan pensejajaran menggunakan program Clustal Omega. Selanjutnya dibuat pohon filogenetik menggunakan program Mega 6.0.

Perancangan kandidat primer SWP EHP dilakukan dengan memilih sekitar 18-23 sekuen nukleotida pada daerah yang lestari yang ditentukan berdasarkan hasil pensejajaran ketujuh sekuen SWP EHP. Primer dirancang menjadi 2 pasang yang setiap pasangnya diberi kode primer SW P-EHP1 dan primer SW P-EHP3.

\section{Persiapan Sampel}

Sampel udang vaname yang digunakan pada penelitian ini sebanyak 24 ekor, diperoleh dari LP2IL (Loka Pemeriksaan Penyakit Ikan dan Lingkungan), Serang. Sementara untuk pengujian spesifitas primer digunakan sampel kepiting yang berasal dari perairan di Lampung dan lobster yang berasal dari perairan di Sukabumi. Sampel yang telah didapatkan tersebut masing-masing di ambil bagian organ insang dan hepatopankreas sekitar 10-30 mg dan diawetkan pada larutan fiksatif berupa ethanol 85\%sebagai persiapan untuk isolasi DNA.

\section{Isolasi DNA}

Isolasi DNA dilakukan dengan menggunakan Genomic DNA Mini Kit (Geneaid). Hasil isolasi DNA kemudian dilakukan pengujian kualitas dan kuantitas DNA nya dengan elektroforesis dan spektrofotometer.

\section{Uji PCR (Polymerase Chain Reaction)}

Reaksi PCR dilakukan menggunakan kedua primer hasil desain pada tahap sebelumnya dan menggunakan kit MyTaq ${ }^{\text {TM }}$ HS Red Mix (BioLine). Sebanyak $1 \mu \mathrm{L}$ DNA hasil isolasi dimasukkan ke dalam tabung $0,2 \mathrm{~mL}$ berisi $12,5 \mu \mathrm{L}$ My Taq HS Red Mix; 0,5 $\mu \mathrm{L}$ Primer-F $(20 \mu \mathrm{M})$; $0,5 \mu \mathrm{L}$ Primer-R (20 iM); dan 10,5 $\mu \mathrm{L} \mathrm{ddH2O} \mathrm{hingga}$ volume reaksi PCR sebanyak $25 \mu \mathrm{L}$. Siklus PCR dimulai dengan denaturasi awal pada suhu $95^{\circ} \mathrm{C}$ selama 1 menit, sebanyak 1 siklus. Kemudian denaturasi pada suhu $95^{\circ} \mathrm{C}$ selama 15 detik. Proses annealing optimal pada suhu $48^{\circ} \mathrm{C}$ selama 15 detik. Proses selanjutnya yaitu ekstensi yang dilakukan pada suhu $72^{\circ} \mathrm{C}$ selama 
10 detik serta ekstensi akhir pada suhu $72^{\circ} \mathrm{C}$ selama 7 menit. Proses denaturasi hingga ekstensi akhir dilakukan sebanyak 30 siklus. Hasil PCR dielektroforesis selama 30 menit dengan tegangan 70 volt dan divisualisasi dengan menggunakan UV Transilluminator.

\section{Uji Spesifitas Primer}

Uji Spesifitas primer dilakukan dengan pengujian PCR terhadap DNA cetakan sampel selain udang vaname yaitu organ insang dan hepatopankreas dari kepiting dan lobster. Hasil yang diperoleh dapat dilihat berdasarkan keberadaan pita DNA pada rentang ukuran $398 \mathrm{bp}$ ataupun $415 \mathrm{bp}$, sesuai dengan ukuran produk PCR masing-masing primer.

\section{Uji Sensitivitas Primer}

Pengujian sensitivitas primer dilakukan dengan mengkloning produk PCR SWP-EHP yang diperoleh dari hasil PCR menggunakan primer-primer di atas. Vektor kloning yang digunakan yaitu vektor $\mathrm{pGEM}^{{ }^{\circledR}}$ T Easy. Proses kloning meliputi 3 tahap utama yaitu: persiapan produk sekuen DNA yang akan diligasi, proses ligasi ke dalam vektor kloning yaitu vektor PGEM ${ }^{\circledR}$-T Easy kemudian dilakukan transformasi pada sel kompeten E. coli DH5 $\alpha$. Terdapat dua plasmid hasil konstruksi yaitu pGEM-EHP1 dan pGEM-EHP3. Metode transformasi yang digunakan yaitu dengan metode kejut panas. Hasil transformasi dikultur pada medium LB padat yang telah mengandung Ampisilin $100 \mathrm{ig} / \mathrm{mL}$, IPTG (100 mM), dan x-gal $(50 \mu \mathrm{g} / \mathrm{mL})$ selama 16 jam. Konfirmasi keberhasilan transformasi dilakukan dengan PCR koloni. Koloni yang diduga positif membawa fragmen gen sisipan dikultur kembali pada medium LB cair yang mengandung Ampisilin 100 ìg/ $\mathrm{mL}$ selama 16 jam. Plasmid diisolasi dengan menggunakan Presto Mini Plasmid Kit (Geneaid). Konstruk plasmid dikonfirmasi kembali dengan reaksi pemotongan menggunakan Fast Digest EcoR1 (Thermo Scientific) dan sekuensing menggunakan primer universal SP6 dan primer T7 (Macrogen, Korea). Sekuen hasil pembacaan kemudian dilakukan pensejajaran pada situs NCBI (https:// blast.ncbi.nlm.nih.gov/Blast.cgi). Plasmid dihitung dengan rumus bilangan Avogadro kemudian dilakukan serial pengenceran untuk digunakan pada pengujian sensitivitas primer. Pengenceran dilakukan hingga 10 kali. Masing-masing plasmid digunakan 1 ì sebagai tempat untuk dilakukan pengujian PCR.

\section{HASIL DAN BAHASAN}

\section{Perancangan Primer}

Perancangan primer untuk uji PCR pada udang vaname yang terinfeksi EHP dilakukan dengan mentarget SWP (Spore Wall Protein) yang terdapat pada EHP. SWP merupakan bagian protein dinding spora yang dimiliki oleh EHP yang bersifat resisten terhadap lingkungan dan berfungsi menjaga morfologi spora. Protein ini diketahui terlibat dalam interaksi inangpatogen pada penambatan spora terhadap permukaan sel inang heparin selama proses infeksi terhadap sel inang (Jaroenlak et al., 2018; Yang et al., 2014). Langkah pertama pada perancangan primer dimulai dengan pencarian semua sekuen SW P EHP yang terdapat pada database (Tabel 1).

Semua sekuen SWP EHP yang diperoleh kemudian dilakukan pensejajaran dan sekuen primer dipilih sekitar 18-23 sekuen dari daerah yang lestari. Perancangan primer yang tepat dan spesifik merupakan hal yang sangat penting untuk menunjang keberhasilan dari reaksi PCR terutama yang bertujuan untuk mendeteksi penyakit. Primer dirancang sebanyak dua pasang yaitu primer SW P-EHP1 dan SWP-EHP3 (Tabel 2). Masing-masing primer dirancang berdasarkan parameter primer yang baik. Menurut Lorenz (2012), parameter primer yang baik meliputi panjang primer yang terdiri atas sekitar 17-30 nukleotida, kandungan GC ideal yaitu $50 \%$ tidak ada sekuen nukleotida tunggal yang berulang 3-4 kali, tidak membentuk struktur sekunder maupun hairpin, tidak komplemen antara dua primer dan perbedaan nilai $\mathrm{T}_{\mathrm{m}}$ (melting temperature) antara primer forward dan reverse tidak lebih dari $5^{\circ} \mathrm{C}$.

\section{Uji PCR (Polymerase Chain Reaction)}

Produk PCR yang dihasilkan menggunakan primer SWP-EHP1 yaitu berukuran $398 \mathrm{bp}$, sedangkan primer SWP-EHP3 yaitu 415 bp. Elektroferogram hasil PCR pada semua sampel dengan menggunakan masingmasing primer SWP-EHP1 dan SWP-EHP3 dapat dilihat pada Gambar 1 dan 2. Jumlah keseluruhan sampel udang vaname yang didapatkan yaitu 24 ekor. Berdasarkan hasil PCR yang diperoleh, 12 sampel ternyata dinyatakan positif terinfeksi EHP dan 12 sampel lainnya negatif EHP. Kedua belas sampel yang dinyatakan positif EHP tersebut di antaranya sampel no $7,8,9,10,11,13,14,16,17,18,19$, dan 21 sedangkan yang negatif EHP yaitu sampel no $1,2,3$, $4,5,6,12,15,20,22,23$, dan 24. Hasil PCR yang diperoleh ini sama antara hasil PCR dengan menggunakan primer SW P-EHP1 maupun SW P-EHP3.

\section{Uji Spesifitas Primer}

Primer yang spesifik pada pengujian PCR untuk tujuan diagnostik sangat penting untuk menghindari terjadinya positif palsu. Pada penelitian ini digunakan sampel lobster dan udang yang memiliki tingkat kekerabatan yang dekat dengan udang. Pada Gambar 
Tabel 1. Sekuen spore wall protein Enterocytozoon hepatopenaei yang terdapat pada database NCBI

Table 1. Enterocytozoon hepatopenaei spore wall protein sequences from $\mathrm{NCBI}$

\begin{tabular}{ll}
\hline Nama kode & No. akses \\
\hline SWP_EHP_A & KX258197.1 \\
SWP_EHP_B & KY483639.1 \\
SWP_EHP_C & KY593133.1 \\
SWP_EHP_D & KY593129.1 \\
SWP_EHP_E & KY674357.1 \\
SWP EHP F & KY593132.2 \\
\hline
\end{tabular}

Tabel 2. Perancangan primer SWP EHP untuk deteksi dini EHP dengan metode PCR Table 2. SWP EHP primer design for early detection of EHP by PCR method

\begin{tabular}{|c|c|c|c|}
\hline \multicolumn{2}{|c|}{ Primer 1 (SWP-EHP1F) } & \multicolumn{2}{|c|}{ Primer 1 (SW P-EHP1R) } \\
\hline Sekuen (Sequence) & CCA TTG GTC AAA TAC AAT TTC & Sekuen (Sequence) & GCA TAA ATT CAT CCA TTT CTA C \\
\hline Panjang basa (Base length ) & 21 & Panjang basa (Base length ) & 22 \\
\hline GC $(\%$ & 33.3 & $\mathrm{GC}(\%)$ & 31.8 \\
\hline $\operatorname{Tm}\left({ }^{\circ} \mathrm{C}\right)$ & 53.5 & $\operatorname{Tm}\left({ }^{\circ} \mathrm{C}\right)$ & 54.7 \\
\hline \multicolumn{2}{|c|}{ Primer 3 (SWP-EHP3F) } & \multicolumn{2}{|c|}{ Primer 3 (SW P-EHP3R) } \\
\hline Sekuen (Sequence) & GGT CAA ATA CAA TTT CAA ACA C & Sekuen (Sequence) & CTC CAT TTA TCA TAC TTA AAT GC \\
\hline Panjang basa (Base length ) & 22 & Panjang basa (Base length ) & 23 \\
\hline GC $(\%$ & 31.8 & $\mathrm{GC}(\%$ & 30.4 \\
\hline $\operatorname{Tm}\left({ }^{\circ} \mathrm{C}\right)$ & 54.7 & $\operatorname{Tm}\left({ }^{\circ} \mathrm{C}\right)$ & 55.7 \\
\hline
\end{tabular}

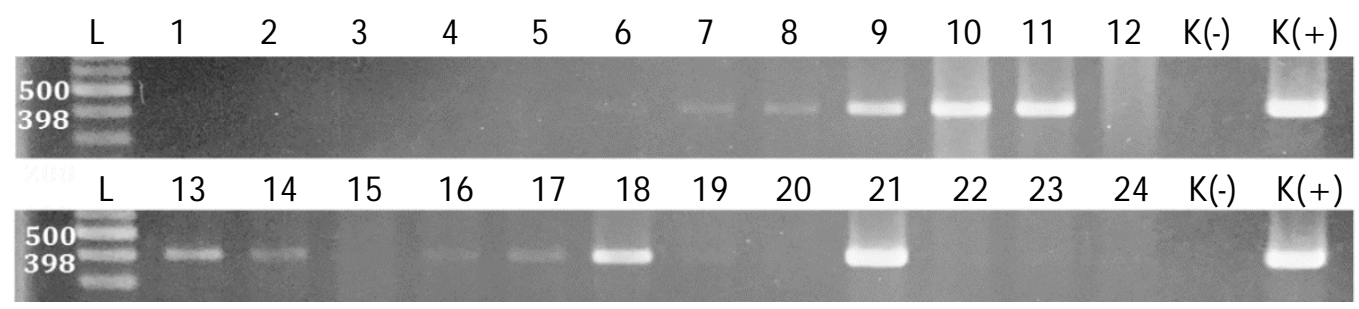

Gambar 1. Elektroferogram hasil PCR semua sampel udang menggunakan primer SWPEHP1. L: ladder 100 pb, sampel: 1-24 (1-18: organ insang \& hepatopankreas; 1924: organ hepatopankreas), $\mathrm{K}(-)$ : Kontrol negatif, $\mathrm{K}(+)$ : Kontrol positif.

Figure 1. Electropherogram PCR result of all shrimp sample using SWP-EHP1 primers. L: ladder 100 bp, sample: 1-24 (1-18:gill \& hepatopancreas; 19-24:hepatopancreas), K(-): Negative control, K(+ ): Positive control.

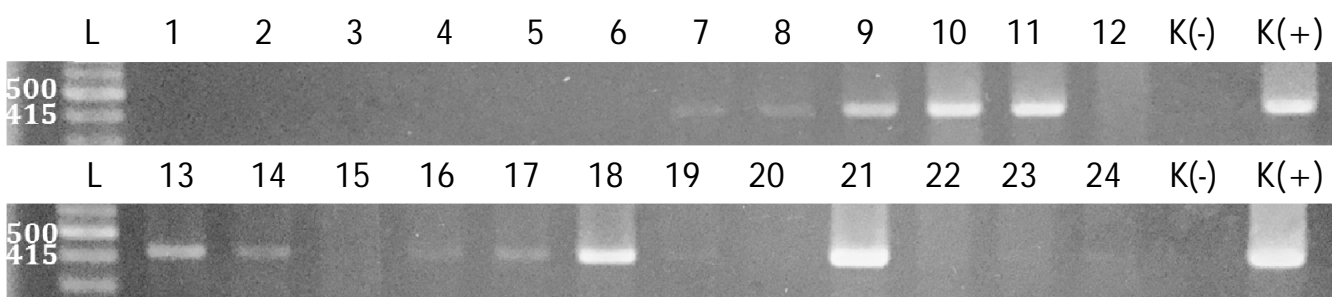

Gambar 2. Elektroferogram hasil PCR semua sampel udang menggunakan primer SWPEHP3. L: ladder 100 pb, sampel: 1-24(1-18: organ insang \& hepatopankreas; 19-24: organ hepatopankreas), K(-): kontrol negatif, $\mathrm{K}(+)$ : kontrol positif.

Figure 2. Electropherogram PCR result of all shrimp sample using SWP-EHP3 primers. L: ladder 100 bp, sample: 1-24 (1-18: gill \& hepatopancreas; 19-24: hepatopancreas), $\mathrm{K}(-)$ : negative control, $\mathrm{K}(+)$ : positive control. 
3, dapat dilihat tidak adanya keberadaan pita DNA pada semua sampel. Hal ini menunjukkan baik lobster dan kepiting bukan merupakan inang yang cocok bagi parasit EHP. Seperti beberapa kasus wabah WFD yang terjadi selama ini di Thailand dan India, organisme yang diserang oleh EHP yaitu organisme penaeid seperti udang vaname (Litopenaeus vannamei) dan udang windu (Penaeus monodon) (Tangprasittipap et al., 2013; Tourtip et al., 2009).

\section{Uji Sensitivitas Primer}

Pengujian sensitivitas dilakukan terhadap rancangan primer SWP-EHP1 dan SWP-EHP3 untuk mengetahui konsentrasi terkecil patogen EHP yang dapat dideteksi dengan PCR menggunakan primer tersebut. Tahap awal yang dilakukan pada pengujian ini yaitu memperbanyak DNA cetakan SWP EHP dengan cara kloning. Kloning merupakan teknik yang digunakan untuk perbanyakan fragmen gen target dengan mengintroduksi DNA rekombinan ke dalam suatu sel inang (Bertero et al., 2017; Brown, \& Vallier, 2017). Uji sensitivitas primer dilakukan terhadap primer SWPEHP1 dan SW P-EHP3, maka pada penelitian ini dibuat 2 konstruk: pGEM-HP1 dan pGEM-HP3.

Keberhasilan hasil transformasi dikonfirmasi melalui beberapa cara, yaitu pertama dengan seleksi antibiotik (Jang \& Magnuson, 2013). Hal ini memungkinkan sel yang telah berhasil ditransformasi untuk bertahan dan tumbuh pada kondisi di mana sel yang tidak membawa transforman akan mati. Sedangkan pada seleksi koloni biru/putih, hidrolisis $X$-gal oleh $\beta$-galactosidase akan menyebabkan warna biru pada koloni dan mengindikasikan bahwa koloni tersebut mengandung vektor tanpa DNA target. Sebaliknya koloni putih mengindikasikan bahwa koloni mengandung insersi DNA target (Padmanabhan et al., 2011). Selanjutnya dilakukan konfirmasi dengan PCR koloni serta analisis menggunakan enzim restriksi EcoR1. Pada plasmid pGEM ${ }^{\circledR}$-T Easy terdapat dua sisi pengenalan oleh EcoR1, maka ketika dilakukan reaksi restriksi hasilnya akan terbentuk 2 pita DNA yaitu pita yang ukuran besar merupakan plasmid dan pita DNA yang berukuran kecil merupakan DNA target. Pada Gambar 4 dapat dilihat elektroferogram hasil reaksi restriksi dari 10 sampel yang diduga membawa gen target. Sumur 1 hingga 6 merupakan konstruk PGEMHP1 sedangkan sumur no 13-16 merupakan PGEMHP3. Hasil restriksi dapat terlihat adanya 2 pita pada semua sampel. Hal ini mengkonfirmasi kembali bahwa hasil transformasi yang dilakukan berhasil.

Konfirmasi terakhir yaitu sekuensing menggunakan primer T7 dan SP6. Berdasarkan hasil BLAST, sekuen teratas yang muncul merupakan 6 sekuen SWP EHP. Hal ini mengkonfirmasi bahwa kloning berhasil dilakukan. Untuk mengetahui hubungan evolusi dari sekuen SWP EHP yang didapatkan pada penelitian ini dengan sekuen SWP EHP beserta SWP dari mikrosporidian lainnya, maka dilakukan pembuatan pohon filogenetika (Gambar 5).

Pada gambar pohon filogenetik, dapat dilihat sekuen isolat SWP pGEM-HP1/pGEM-HP1berada pada klade yang sama dengan SWP EHPA-B karena memiliki ansestor yang sama dibandingkan dengan SWP D. Diketahui bahwasanya sekuen SWP EHP kode D berasal dari Venezuela sedangkan SWP EHP kode lainnya berasal dari Asia Tenggara (Tang et al., 2017). Dilihat berdasarkan hasil pensejajaran (Gambar 6), pada deretan sekuen SWP pGEM-HP1/pGEM-HP3 EHP yang didapatkan pada penelitian ini terdapat perbedaan satu nukleotida yaitu $G$ yang mana pada sekuen SWP EHP keenam kode lainnya menunjukkan A. Hal ini dapat disebut juga dengan subtitusi transisi. Perubahan yang terjadi kemungkinan dapat disebabkan oleh faktor lingkungan (Rùziièka et al., 2017). Perbedaan ini juga bisa diakibatkan karena SWP EHP yang digunakan diperoleh dari negara yang berbeda. Walaupun demikian, apabila sekuen nukleotida SW P pGEM-HP1/ pGEM-HP3 EHP ditranslasikan, tidak menyebabkan perubahan asam amino proteinnya. Apabila dilihat berdasarkan hasil BLAST, nilai identity antara sekuen SWP EHP dalam penelitian ini dengan SW P EHP lainnya mencapai 99\% Dilihat dari parameter lainnya seperti
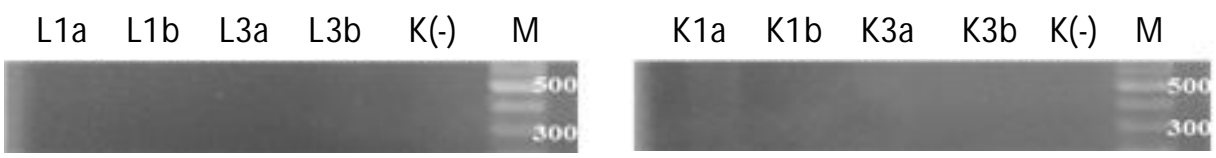

Gambar 3. Elektroferogram hasil PCR sampel lobster dan kepiting menggunakan primer SWP-EHP1 dan SWP-EHP3. M: ladder 100 pb, L: lobster, K: kepiting, 1: primer SWP-EHP1, 3: primer SWP-EHP3, a: insang, $b$ : hepatopankreas, dan K(-): kontrol negatif.

Figure 3. Electropherogram PCR result of lobster and crab samples using SWP-EHP1 and SWP-EHP3 primers. M: ladder $100 \mathrm{bp}$, L: lobster, K: crab, 1: primer SWP-EHP1, 3: primer SW P-EHP3, a: gill, b: hepatopancreas and K(-): negative control. 
M 123456713141516

Deteksi dini Enterocytozoon hepatopenaei (EHP) pada udang vaname ..... (Annisa Fitriah Faisal )

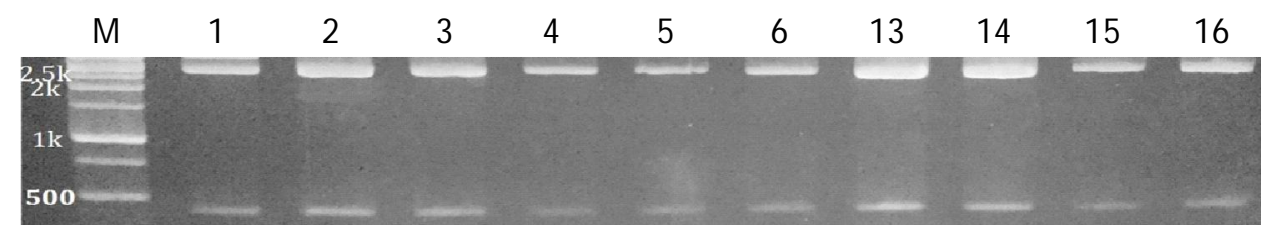

Gambar 4. Elektroforegram hasil reaksi restriksi menggunakan EcoR1. Keterangan: M: ladder 1Kb, 1-6: sampel pGEM-HP1, 13-16: sampel pGEM-HP3.

Figure 4. Electropherogram restriction result using EcoR1. M: ladder $1 \mathrm{~Kb}, 1-6$ : pGEMHP1 sample, 13-16: pGEM-HP3 sample.

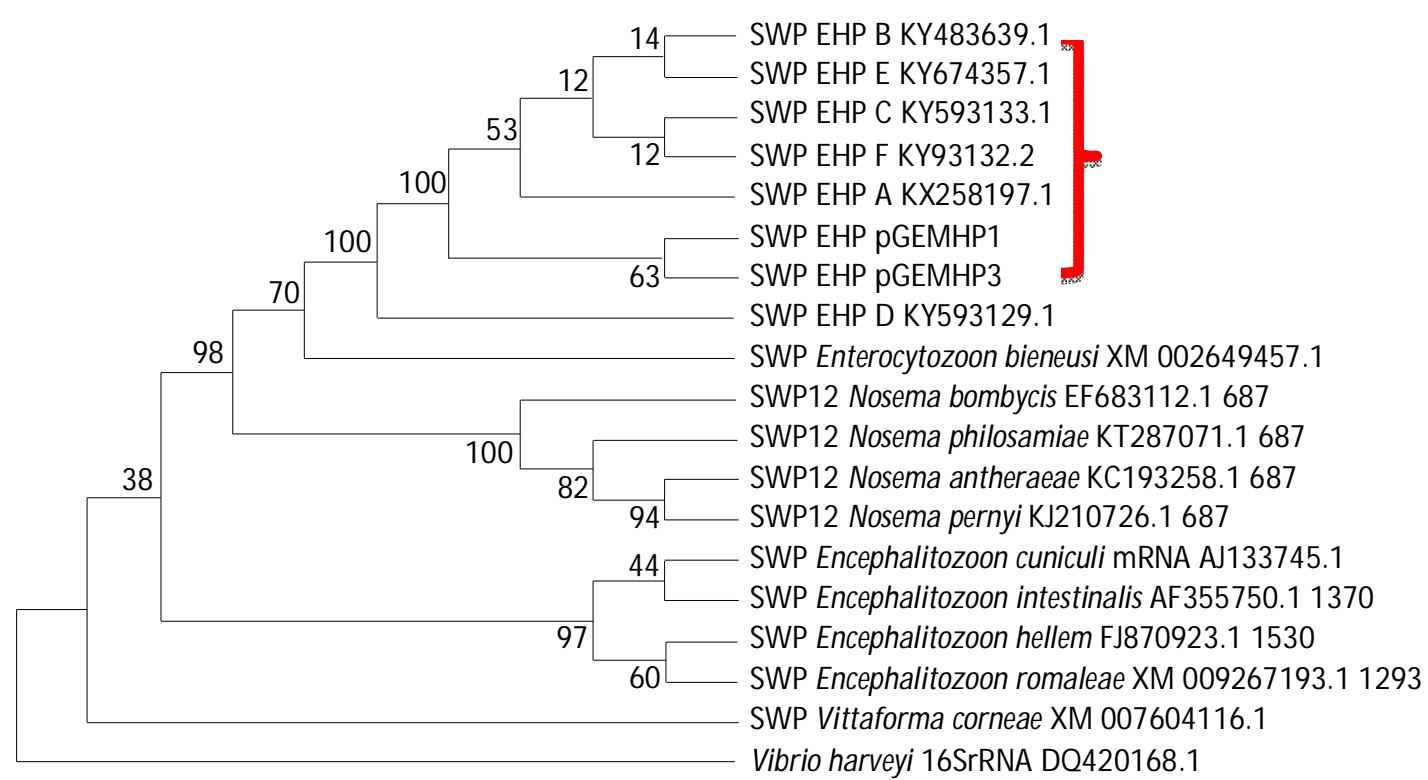

Gambar 5. Pohon filogenetika pGEM-HP1 dan pGEM-HP3 beserta SWP lainnya.

Figure 5. Phylogenetic tree of PGEM-HP1 and PGEM-HP3 with other SWP.

max score, e-value, dan lain-lain bisa disimpulkan bahwa sekuen SWP EHP ini memiliki tingkat similaritas yang tinggi dengan SWP EHP lainnya. Menurut Pearson (2014), pencarian tingkat similaritas sekuen DNA merupakan salah satu cara untuk mengidentifikasi sekuen homolog. Apabila ada dua/lebih sekuen yang berbagi lebih banyak kesamaan, maka bisa dikatakan bahwa kedua sekuen tersebut homolog. Adapun sekuen SWP EHP pada penelitian ini dapat disimpulkan homolog dengan sekuen SWP EHP kelima kode lainnya.

Proses terakhir yaitu pengujian sensitivitas kedua pasang primer dengan dilakukan PCR terhadap serial pengenceran pGEM-HP1 maupun pGEM-HP3 sehingga tingkat sensitivitas primer dalam mendeteksi EHP dapat diketahui. Hasil perhitungan dapat diketahui jumlah kopi pGEM-HP1 yaitu 7,74 x $10^{10} \mathrm{kopi}$ dan pGEM-HP3 yaitu $16,2 \times 10^{10}$ kopi. Pada elektroferogram hasil PCR serial pengenceran pGEMHP1dan pGEM-HP3, dapat dilihat keberadaan pita DNA terdapat pada pengenceran $10^{10}$ hingga $10^{2}$
(Gambar 7). Hal ini dapat disimpulkan bahwa primer SWP-EHP1 dapat mendeteksi EHP hingga 7,74 x 102 kopi sedangkan primer SWP-EHP3 dapat mendeteksi hingga 16,2 x 10² kopi. Menurut Lorenz (2012), jumlah molekul target yang optimal untuk reaksi PCR yaitu berkisar antara $10^{4}-10^{7}$ kopi DNA. Hasil penelitian ini tentunya belum melebihi spesifikasi deteksi menggunakan real time PCR. Pada penelitian (Forootan et al., 2017), diketahui bahwa jumlah DNA target terendah yang yang dapat terdeteksi menggunakan real time PCR yaitu hingga $\pm 2,5$ molekul.

\section{KESIMPULAN}

Deteksi dini keberadaan infeksi Enterocytozoon hepatopenaei (EHP) padaudang vaname dapat dilakukan dengan uji PCR menggunakan pasangan primer SWPEHP1 dan SWP-EHP3 (Forward dan Reverse). Hasil pengujian sensitivitas primer, diketahui bahwa primer SWP-EHP1 dapat mendeteksi EHP hingga 7,74 x 102 kopi sedangkan primer SWP-EHP3 dapat mendeteksi hingga $16,2 \times 10^{2} \mathrm{kopi}$. 
SWP_EHP_D_KY593129.1 SWP_EHP_PGEMHP 3 SWP_EHP_PGEMHP 1 SWP_EHP_B_KY 483639.1 SWP_EHP_E_KY 674357.1 SWP_EHP_A_KX258197.1 SWP_EHP_C_KY593133.1 SWP_EHP_F_KY593132.2

SWP_EHP_D_KY593129.1 SWP_EHP_PGEMHP 3 SWP_EHP_PGEMHP 1 SWP_EHP_B_KY 483639.1 SWP_EHP_E_KY 674357.1 SWP_EHP_A_KX258197.1 SWP_EHP_C_KY 593133.1 SWP_EHP_F_KY593132.2

SWP_EHP_D_KY593129.1 SWP_EHP_PGEMHP 3 SWP_EHP_B_KY483639.1 SWP_EHP_E_KY 674357.1 SWP_EHP_A_KX258197.1 SWP_EHP_C_KY593133.1 SWP_EHP_F_KY593132.2

SWP_EHP_D_KY 593129.1 SWP_EHP_PGEMHP 3 SWP_EHP_PGEMHP 1 SWP_EHP_B_KY 483639.1 SWP_EHP_E_KY 674357.1 SWP_EHP_A_KX258197.1 SWP_EHP_C_KY 593133.1 SWP_EHP_F_KY593132.2

SWP_EHP_D_KY593129.1 SWP_EHP_PGEMHP 3 SWP_EHP_PGEMHP 1 SWP_EHP_B_KY 483639.1 SWP_EHP_E_KY 674357.1 SWP_EHP_A_KX258197.1 SWP_EHP_C_KY593133.1 SWP_EHP_F_KY593132.2

SWP_EHP_D_KY593129.1 SWP_EHP_PGEMHP 3 SWP_EHP_PGEMHP 1 SWP_EHP_B_KY 483639.1 SWP_EHP_E_KY 674357.1 SWP_EHP_A_KX258197.1 SWP_EHP_C_KY593133.1 SWP_EHP_F_KY593132.2

SWP_EHP_D_KY593129.1 SWP_EHP_PGEMHP 3 SWP_EHP_PGEMHP 1 SWP_EHP_B_KY 483639.1 SWP_EHP_E_KY 674357.1 SWP_EHP_A_KX258197.1 SWP_EHP_C_KY593133.1 SWP_EHP_F_KY593132.2

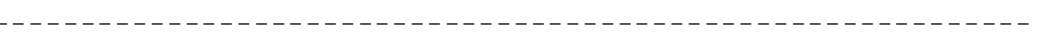
(1) 作 -GgTtTAAGTAATTACGAGTTTGGCGGCACAATTCTCAAACA -TTGCAGAGTGTTGTTAAGGGTTAAATAATTACGAGTTTGGCGGCACAATTCTCAAACA -AAGTAATTACGAGTTTGGCGGCACAATTCTCAAACA

-TTtCATCATtGgTCAAATACAATTTCAAACACGGTAAATCTTAAAGCTTTAAAGAGAGA ---n-----_GGTCAAATACAATTTCAAACACTGTAAACCTTAAAGCATTAAAAAGAGA -----CCATTGGTCAAATACAATTTCAAACACTGTAAACCTTAAAGCATTAAAAAGAGA TTTTCACCATTGGTCAAATACAATTTCAAACACTGTAAACCTTAAAGCATTAAAAAGAGA TTTTCACCATTGGTCAAATACAATTTCAAACACTGTAAACCTTAAAGCATTAAAAAGAGA TTTTCACCATTGGTCAAATACAATTTCAAACACTGTAAACCTTAAAGCATTAAAAAGAGA TTTTCACCATTGGTCAAATACAATTTCAAACACTGTAAACCTTAAAGCATTAAAAAGAGA TTTTCACCATTGGTCAAATACAATTTCAAACACTGTAAACCTTAAAGCATTAAAAAGAGA

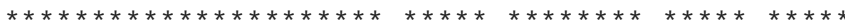

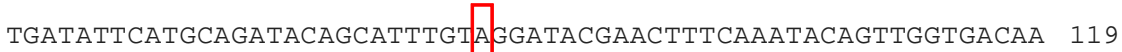
CGATATTTACACAGACACAGCATTTGTGGGATATGAGCTTTCAAATACAGTTGGAGACAA 109 CGATATTTACACAGACACAGCATtTGTGGGATATGAGCTTTCAAATACAGTTGGAGACAA 114 CGATATTACACAGACACAGCATTTGTAGGATATGAGCTTTCAAATACAGTTGGAGACAA 180 CGATATTAACACAGACACAGCATTTGTAGGATATGAGCTTTCAAATACAGTTGGAGACAA 161 CGATATTACACAGACACAGCATTTGTAGGATATGAGCTTTCAAATACAgTTGGAGACAA 179 CGATATTTACACAGACACAGCATTTGTAGGATATGAGCTTTCAAATACAGTTGGAGACAA 156 CGATATtTACACAGACACAGCATtTGTAGGATATGAGCTTtCAAATACAGTTGGAGACAA 156

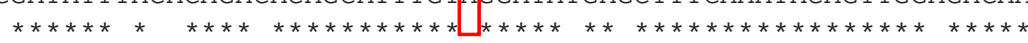

GCAACTAAAAGAAGTTTGTAATGATTtTTCTAAAGCATACGAATGTATAGCAGAAGATAA 179 ACAGCTTAAAGAAGTTTGCAATGATTTTTCTAAAGCATATGAATGCATATCAGAAGATAA 169 ACAGCTTAAAGAAGTtTGCAATGATtTtTCTAAAGCATAtGAATGCATAtCAGAAGATAA 174 ACAGCTTAAAGAAGTTTGCAATGATTTTTCTAAAGCATATGAATGCATATCAGAAGATAA 240 ACAGCTTAAAGAAgTTTGCAATGATtTTTCTAAAGCATATGAATGCATATCAGAAGATAA 221

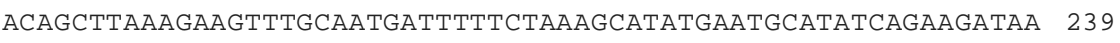
ACAGCTTAAAGAAGTTTGCAATGATtTTtCTAAAGCATATGAATGCATATCAGAAGATAA 216

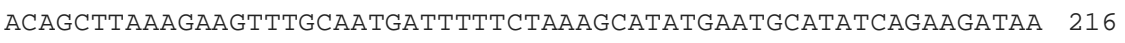

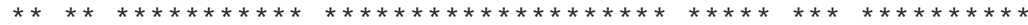

AAGAAAAATGAATGAAAAAATGGGAGATATTTTTGAAGAgTtGAgtATtTTAAAAAAGAA 239 AAGGAAAATGAATGAAAAAATGGGAGATATTTTGAAGAATTAAgtATtTTAAAAAAGAA 229 AAgGAAAATGAATGAAAAAATGGGAGATATTTTTGAAGAATTAAgTATTTTAAAAAAGAA 234 AAGGAAAATGAATGAAAAAATGGGAGATATTTTTGAAGAATTAAGTATTTTAAAAAAGAA 300 AAGGAAAATGAATGAAAAAATGGGAGATATTtTtGAAGAATTAAGTATTTTAAAAAAGAA 281 AAGGAAAATGAATGAAAAAATGGGAGATATTTTGAAGAATTAAGTATTTAAAAAAAGA 299 AAGGAAAATGAATGAAAAAATGGGAGATATTTTTGAAGAATTAAGTATTTTAAAAAAGAA 276 AAGGAAAATGAATGAAAAAATGGGAGATATtTtTGAAGAAtTAAgtAtTtTAAAAAAGAA 276

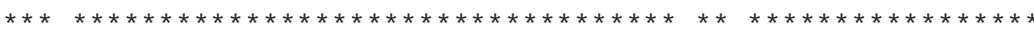

ATGCAAACAAATTGATCATCAACGTAAAACTGTAAGCAATTTGAGATATGATTTAGAAGA 299 GTGCAAACAAATTGATCATCAACGCAAAACTGTAAATAACCTAAGATATGATTTAGAAGA 289 GTGCAAACAAATTGATCATCAACGCAAAACTGTAAATAACCTAAGATATGATTTAGAAGA 294 GTGCAAACAAATTGATCATCAACGCAAAACTGTAAATAACCTAAGATATGATTTAGAAGA 360 GTGCAAACAAATTGATCATCAACGCAAAACTGTAAATAACCTAAGATATGATTTAGAAGA 341 GTGCAAACAAATTGATCATCAACGCAAAACTGTAAATAACCTAAGATATGATTTAGAAGA 359 GTGCAAACAAATTGATCATCAACGCAAAACTGTAAATAACCTAAGATATGATTTAGAAGA 336 GTGCAAACAAATTGATCATCAACGCAAAACTGTAAATAACCTAAGATATGATTTAGAAGA 336

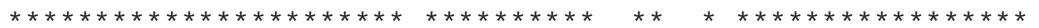

AATATTACAATCAAATATTTATAAAgAAgATCAAAAAGAAAATTTAGAAAAAAAGTTAgG 359 AATATtGCAATCAAACATTTATAAAGAAGATCAAAAAGAAAATTTAGAAAAAAAATTAGG 349 AATATTGCAATCAAACATTTATAAAGAAGATCAAAAAGAAAATTTAGAAAAAAAATTAgG 354 AATATTGCAATCAAACATTTATAAAGAAGATCAAAAAGAAAATTTAGAAAAAAAATTAGG 420 AATATTGCAATCAAACATTTATAAAGAAGATCAAAAAGAAAATTTAGAAAAAAAATTAgG 401 AATATTGCAATCAAACATTTATAAAGAAGATCAAAAAGAAAATTTAGAAAAAAAATTAgG 419 AATATTGCAATCAAACATTTATAAAGAAGATCAAAAAGAAAATTTAGAAAAAAAATTAGG 396 AATATTGCAATCAAACATtTAtAAAGAAGATCAAAAAGAAAATTTAGAAAAAAAATTAgG 396

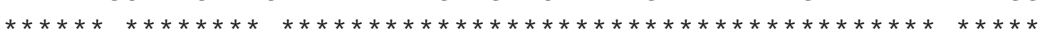




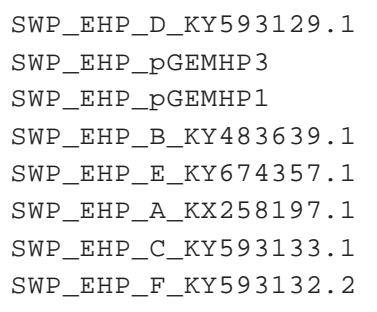

SWP_EHP_D_KY 593129.1 SWP_EHP_PGEMHP 3

SWP_EHP_PGEMHP 1

SWP_EHP_B_KY 483639.1

SWP_EHP_E_KY 674357.1

SWP_EHP_A_KX258197.1

SWP_EHP_C_KY 593133.1

SWP_EHP_F_KY593132.2

SWP_EHP_D_KY593129.1

SWP_EHP_PGEMHP 3

SWP_EHP_PGEMHP 1

SWP_EHP_B_KY 483639.1

SWP_EHP_E_KY 674357.1

SWP_EHP_A_KX258197.1

SWP_EHP_C_KY 593133.1

SWP_EHP_F_KY593132.2

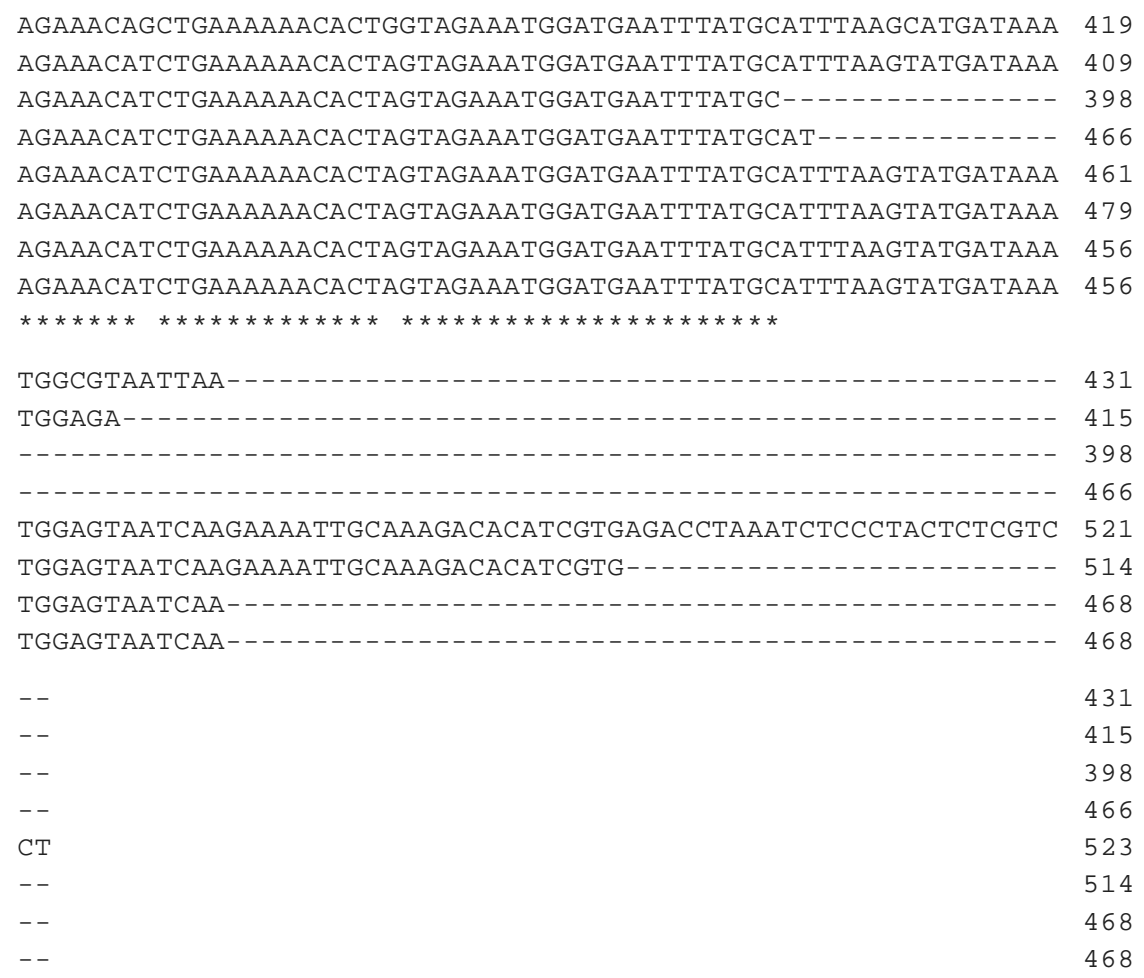

AGAAACAGCTGAAAAAACACTGGTAGAAATGGATGAATtTATGCATtTAAGCATGATAAA 419 AGAAACATCTGAAAAAACACTAGTAGAAATGGATGAATtTATGCAtTTAAGTAtGATAAA 409

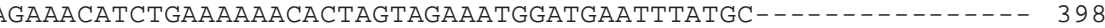
ATTATTCATTIAAGTATGATAAA 461 AGAAACATCTGAAAAAACACTAGTAGAAATGGATGAATtTATGCATtTAAGTATGATAAA 456 AGAAACATCTGAAAAAACACTAGTAGAAATGGATGAATtTATGCATtTAAgTAtGATAAA 456

Gambar 6. Hasil pensejajaran sekuen pGEM-HP1 dan pGEM-HP3 dengan SWP-EHP kode lainnya.

Figure 6. Multiple sequence alignment result of PGEM-HP1 and pGEM-HP3 with other SWP EHP code sequences.

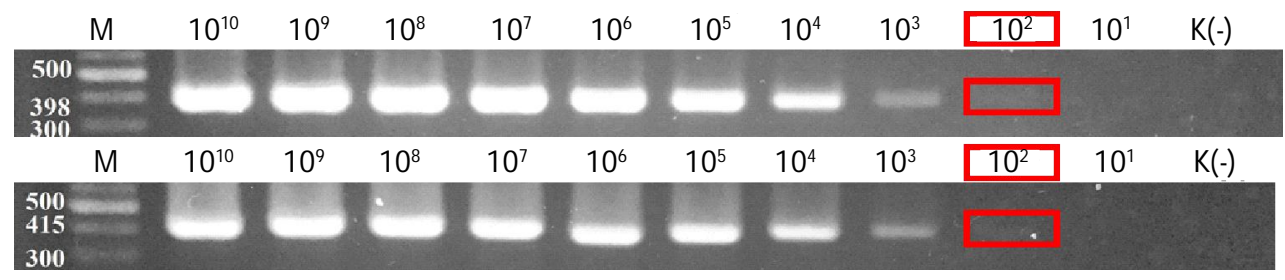

Gambar 7. Elektroferogram hasil PCR serial pengenceran pGEM-HP1 (atas) dan pGEMHP3 (bawah). L: ladder 100 bp, 1-10: pengenceran 1010 $10^{1}$ dan K(-): kontrol negatif.

Figure 7. Electropherogram PCR result of pGEM-HP1(Top) and pGEM-HP3 (bottom) serial dilution. L: ladder $100 \mathrm{bp}, 1-10$ : dilution of $10^{10}-10^{1}$ and $\mathrm{K}(-)$ : negative control.

\section{UCAPAN TERIMA KASIH}

Penelitian ini dibiayai oleh Program Penelitian, Pengabdian kepada Masyarakat, dan Inovasi (P3MI) Kelompok Keahlian ITB. Ucapan terima kasih juga disampaikan kepada Loka Pemeriksaan Penyakit Ikan dan Lingkungan (LP2IL) Serang, yang telah membantu dalam penyediaan sampel udang vaname.

\section{DAFTAR ACUAN}

Aristiyani, R. (2017). Analisa Daya Saing Udang Indonesia di Pasar Internasional. Universitas Lampung.
Bertero, A., Brown, S., \& Vallier, L. (2017). Methods of Cloning. Basic Science Methods for Clinical Researchers. Elsevier Inc.

Dirjen Perikanan Budidaya. (2014). Data Statistik Series Produksi Perikanan Budidaya Indonesia. Direktorat Jenderal Perikanan Budidaya, Kementerian Kelautan \& Perikanan.

Forootan, A., Sjöback, R., Björkman, J., Sjögreen, B., Linz, L., \& Kubista, M. (2017). Methods to determine limit of detection and limit of quantification in quantitative real-time PCR ( $q P C R$ ). Biomolecular Detection and Quantification, 12, 1-6. 
Jang, C. \& Magnuson, T. (2013). A Novel Selection Marker for Efficient DNA Cloning and Recombineering in E . coli, PLOS ONE, 8(2), 1-7.

Jaroenlak, P., Boakye, D.W., Vanichviriyakit, R., Williams, B.A.P., Sritunyalucksana, K., \& Itsathitphaisarn, O. (2018). Identification, characterization and heparin binding capacity of a sporewall, virulence protein from the shrimp microsporidian, Enterocytozoon hepatopenaei (EHP). Parasites and Vectors, 11(1), 1-15.

Lorenz, T.C. (2012). Polymerase Chain Reaction: Basic Protocol Plus Troubleshooting and Optimization Strategies. Journal of Visualized Experiments, (63), 1-15.

Padmanabhan, S., Banerjee, S., \& Mandi, N. (2011). Screening of Bacterial Recombinants: Strategies and Preventing False Positives. Molecular CloningSelected Applications in Medicine and Biology.

Pearson, W.R. (2014). An Introduction to Sequence and Series. International Journal of Research, 1(10), 1286-1292.

Rajendran, K.V., Shivam, S., Ezhil Praveena, P., Joseph Sahaya Rajan, J., Sathish Kumar, T., Avunje, S., \& Vijayan, K. K. (2016). Emergence of Enterocytozoon hepatopenaei (EHP) in farmed Penaeus (Litopenaeus) vannamei in India. Aquaculture, 454, 272-280.

Rùziièka, M., Kulha'nek, P., Radova', L., Ėechova', A., Sjpaèkova', N., \& Fajkusova', L. (2017). DNA mutation motifs in the genes associated with inherited diseases, PLOS ONE, 12(8), 1-16.

Selvin, J., Ninawe, A., Ramu, M., \& Kiran, S. (2015). Control of Pathogenic Vibrios in Shrimp Aquaculture using Antiinfectives from Marine Natural Products. Conference Papper, p .102-141.
Tang, K.F.J., Aranguren, L.F., Piamsomboon, P., Han, J.E., Maskaykina, I.Y., \& Schmidt, M.M. (2017). Detection of the microsporidian Enterocytozoon hepatopenaei (EHP) and Taura syndrome virus in Penaeus vannamei cultured in Venezuela. Aquaculture, 480, 17-21.

Tang, K.F.J., Han, J.E., Aranguren, L.F., White-Noble, B., Schmidt, M.M., Piamsomboon, P., \& Hanggono, B. (2016). Dense populations of the microsporidian Enterocytozoon hepatopenaei (EHP) in feces of Penaeus vannamei exhibiting white feces syndrome and pathways of their transmission to healthy shrimp. Journal of Invertebrate Pathology, 140, 1-7.

Tangprasittipap, A., Srisala, J., Chouwdee, S., Somboon, M., Chuchird, N., Limsuwan, C., \& Sritunyalucksana, K. (2013). The microsporidian Enterocytozoon hepatopenaei is not the cause of white feces syndrome in whiteleg shrimp Penaeus (Litopenaeus) vannamei. BMC Veterinary Research, 9.

Tourtip, S., Wongtripop, S., Stentiford, G.D., Bateman, K.S., Sriurairatana, S., Chavadej, J., \& Withyachumnarnkul, B. (2009). Enterocytozoon hepatopenaei sp. nov. (Microsporida: Enterocytozoonidae), a parasite of the black tiger shrimp Penaeus monodon (Decapoda: Penaeidae): Fine structure and phylogenetic relationships. Journal of Invertebrate Pathology, 102(1), 21-29.

Yang, D., Dang, X., Tian, R., Long, M., Li,C., Li, T., \& Zhou, Z. (2014). Development of an approach to analyze the interaction between Nosema bombycis (microsporidia) deproteinated chitin spore coats and spore wall proteins. Journal of Invertebrate Pathology, 115(1), 1-7. 